\title{
Different Sensory Systems Share Projection Neurons But Elicit Distinct Motor Patterns
}

\author{
Dawn M. Blitz, ${ }^{\star}$ Mark P. Beenhakker, ${ }^{*}$ and Michael P. Nusbaum \\ Department of Neuroscience, University of Pennsylvania School of Medicine, Philadelphia, Pennsylvania 19104-6074
}

\begin{abstract}
Considerable research has focused on issues pertaining to sensorimotor integration, but in most systems precise information remains unavailable regarding the specific pathways by which different sensory systems regulate any single central pattern-generating circuit. We address this issue by determining how two muscle stretch-sensitive neurons, the gastropyloric receptor neurons (GPRs), influence identified projection neurons that regulate the gastric mill circuit in the stomatogastric nervous system of the crab and then comparing these actions with those of the ventral cardiac neuron (VCN) mechanosensory system. Here, we show that the GPR neurons activate the gastric mill rhythm in the stomatogastric ganglion (STG) via their excitation of two identified projection neurons, modulatory commissural neuron 1 (MCN1) and commissural projection neuron 2 (CPN2), in the commissural ganglion. Support for this conclusion comes from the ability of the modulatory proctolin neuron (MPN), a projection neuron that suppresses the gastric mill rhythm via its inhibitory actions on MCN1 and CPN2, to inhibit the GPR-elicited gastric mill rhythm. Selective elimination of MCN1 and CPN2 access to the STG also prevents GPR activation of this rhythm. The VCN neurons also elicit the gastric mill rhythm by coactivating MCN1 and CPN2, but the GPR-elicited gastric mill rhythm is distinct. These distinct rhythms are likely to result partly from different MCN1 activity levels under these two conditions and partly from the presence of additional GPR actions in the STG. These results support the hypothesis that different sensory systems differentially regulate neuronal circuit activity despite their convergent actions on a single subpopulation of projection neurons.
\end{abstract}

Key words: gastric mill circuit; stomatogastric ganglion; central pattern generator; neuromodulation; rhythms; convergence

\section{Introduction}

Distinct motor patterns can be selected from individual motor circuits by selective activation of different modulatory projection neurons (Perrins and Weiss, 1996; Nusbaum et al., 2001). Recently, attention has turned to determining how coordinate activation of a population of distinct projection neurons, as can occur via activation of a specific sensory pathway, influences motor circuit output (Combes et al., 1999a,b; Gahtan et al., 2002; Beenhakker and Nusbaum, 2004). In some motor systems related but distinct sensory cues are thought to elicit different motor outputs as a result of their activation of overlapping but distinct sets of projection neurons (Kristan and Shaw, 1997; Deliagina et al., 2002; Pouget et al., 2003).

To understand more fully how individual sensory pathways influence the population of projection neurons that regulate motor circuit output, we studied the actions of the paired gastropy-

\footnotetext{
Received Aug. 5, 2004; revised Nov. 8, 2004; accepted Nov. 8, 2004.

This work was supported by National Institute of Neurological Disorders and Stroke Grants NS42813 and NS29436 (M.P.N.), Grant F31-NS41894 (M.P.B.), National Science Foundation Grant IBN 9808356 (M.P.N.), and training grants from the National Institute of Mental Health (T32-MH17168) and the National Institute of General Medical Services (T32-GM07517)

*D.M.B. and M.P.B. contributed equally to this work.

Correspondence should be addressed to Dr. Michael P. Nusbaum, Department of Neuroscience, University of Pennsylvania School of Medicine, 215 Stemmler Hall, Philadelphia, PA 19104-6074. E-mail:nusbaum@mail.med.upenn.edu.

D. M. Blitz's present address: Department of Neurobiology, Harvard Medical School, Boston, MA 02115.

M. P. Beenhakker's present address: Department of Neurology, Stanford University, Stanford, CA 94305

DOl:10.1523/JNEUROSCI.3219-04.2004

Copyright $\odot 2004$ Society for Neuroscience $\quad 0270-6474 / 04 / 2411381-10 \$ 15.00 / 0$
}

loric receptor (GPR) sensory neurons on the gastric mill (chewing) motor circuit in the stomatogastric nervous system (STNS) of the crab Cancer borealis (Nusbaum and Beenhakker, 2002). The gastric mill circuit is one of two motor circuits located in the stomatogastric ganglion (STG). The GPR sensory neurons are muscle stretch-sensitive, multi-transmitter neurons that project to the STG and to the neighboring commissural ganglia (CoGs) (Katz et al., 1989; Katz and Harris-Warrick, 1990). The STG circuits are influenced by $\sim 20$ projection neurons, most of which originate in the CoGs and oesophageal ganglion (OG) (Coleman et al., 1992).

Four of the CoG projection neurons are identified in C. borealis, including modulatory commissural neurons 1,5 , and 7 (MCN1, MCN5, MCN7) and commissural projection neuron 2 (CPN2) (Coleman and Nusbaum, 1994; Norris et al., 1994, 1996; Blitz et al., 1999; Beenhakker and Nusbaum, 2004). When activated individually, each of these projection neurons influences a subset of gastric mill neurons, but selective activation of only MCN1 or CPN2 elicits the gastric mill rhythm. All four of these projection neurons are activated by the ventral cardiac neuron (VCN) mechanosensory system, which also elicits the gastric mill rhythm (Beenhakker et al., 2004). However, only MCN1 and CPN2 contribute to the VCN-elicited gastric mill rhythm (Beenhakker and Nusbaum, 2004).

Here we examine the influence of the GPR neurons on the gastric mill circuit to elucidate how distinct sensory pathways (VCN, GPR) affect the same motor circuit. We show that GPR 


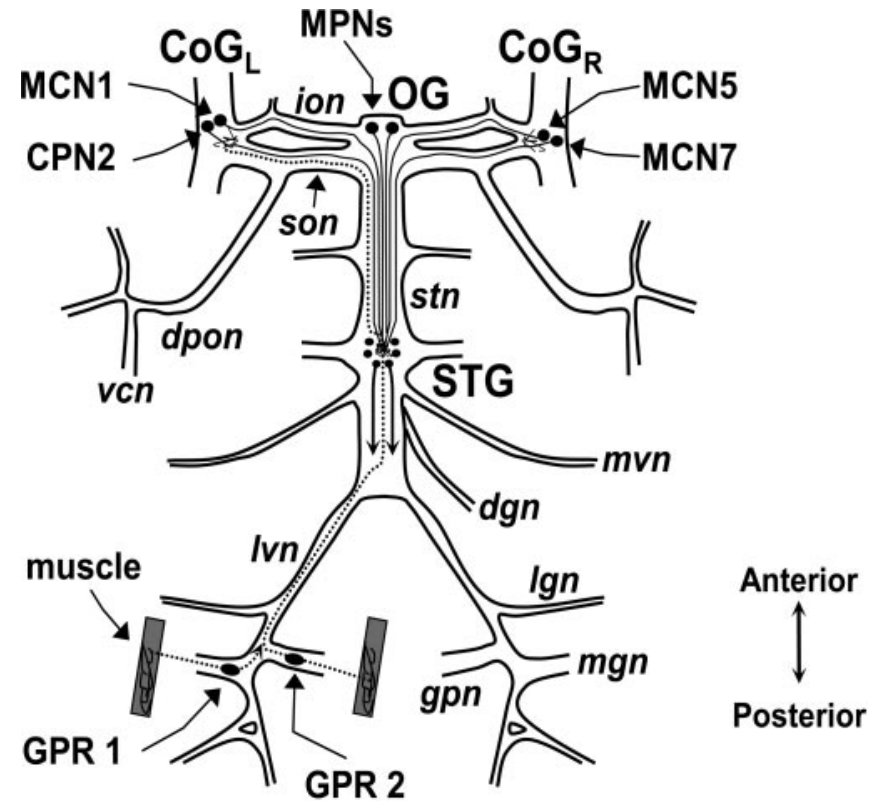

Figure 1. Schematic of the stomatogastric nervous system, including somata location and axonal pathways of the bilateral pair of GPR sensory neurons and the identified projection neurons that innervate the STG. Each GPR projects to and arborizes within the STG and each COG (Katz et al., 1989). There is a single MCN1, CPN2, MCN5, and MCN7 in each CoG and two MPNs in the $0 \mathrm{G}$. For clarity, the complete projection of only one copy of each projection neuron is shown. $d p o n$, Dorsal posterior oesophageal nerve; Ivn, lateral ventricular nerve; $m v n$, medial ventricular nerve; $v c n$, ventral cardiac nerve.

stimulation routinely activates the gastric mill rhythm for the duration of stimulation and a few minutes longer. GPR stimulation also excites all four identified CoG projection neurons, albeit to different degrees, but we demonstrate by their selective removal that only MCN1 and CPN2 are necessary to enable the GPR-elicited gastric mill rhythm. Several aspects of the GPRelicited gastric mill rhythm are distinct from the VCN-elicited rhythm, but they both elicit the gastric mill rhythm via their activation of MCN1 and CPN2. Consequently, distinct sensory pathways can sculpt neural circuit output differentially despite their activation of the same projection neurons.

Some of this work has appeared in abstract form (Blitz and Nusbaum, 1996).

\section{Materials and Methods}

Animals. Male crabs (C. borealis) were obtained from commercial suppliers (Commercial Lobster and Seafood, Boston, MA) and the Marine Biological Laboratory (Woods Hole, MA) and were maintained in aerated artificial seawater at $10-12^{\circ} \mathrm{C}$. Animals were cold anesthetized by being packed in ice for at least $30 \mathrm{~min}$ before dissection. The foregut was removed from the animal, and the dissection of the STNS from the foregut was performed in physiological saline at $\sim 4^{\circ} \mathrm{C}$.

Solutions. C. borealis physiological saline contained the following (in mм): $440 \mathrm{NaCl}, 26 \mathrm{MgCl}_{2}, 13 \mathrm{CaCl}_{2}, 11 \mathrm{KCl}, 10$ Trisma base, 5 maleic acid, pH 7.4-7.6.

Electrophysiology. Electrophysiology experiments were performed by using standard techniques for this system (Beenhakker et al., 2004). The isolated STNS (Fig. 1) was pinned down in a silicone elastomer-lined (Sylgard 184, KR Anderson, Santa Clara, CA) Petri dish. All preparations were superfused continuously with $C$. borealis saline $\left(10-13^{\circ} \mathrm{C}\right)$. Extracellular recordings were made by isolating a region of nerve with petroleum jelly (Vaseline, Chesebrough-Ponds, Greenwich, CT) and pressing one of a pair of stainless steel wire electrodes into the Sylgard within the well, with the second electrode pressed into the Sylgard in the electrically grounded main bath compartment.
To facilitate intracellular recording, we viewed the desheathed ganglia with light transmitted through a dark-field condenser (Nikon, Tokyo, Japan). Intrasomatic recordings were made with microelectrodes (15-30 $\mathrm{M} \Omega$ ) filled with potassium acetate $(4 \mathrm{M})$ and $\mathrm{KCl}(20 \mathrm{~mm})$. Intra-axonal recordings were made with microelectrodes $(20-30 \mathrm{M} \Omega$ ) filled with $\mathrm{KCl}$ (1 M) (Coleman et al., 1995). Recordings were made via Axoclamp 2 amplifiers (Axon Instruments, Foster City, CA). Current injections were performed in single-electrode discontinuous current-clamp (DCC) mode with sample rates between 2 and $3 \mathrm{kHz}$.

STG neurons were identified on the basis of their axonal projections, activity patterns, and interactions with other STG neurons (Weimann et al., 1991; Norris et al., 1996; Bartos and Nusbaum, 1997; Blitz and Nusbaum, 1997). Projection neurons were identified by their soma location, axonal projection pattern, and influence on the STG neurons (Nusbaum and Marder, 1989a,b; Coleman and Nusbaum, 1994; Norris et al., 1994, 1996; Bartos and Nusbaum, 1997; Blitz et al., 1999). Each projection neuron occurs either as a single copy in each CoG (MCN1, MCN5, MCN7, CPN2) or as a functionally equivalent pair in the OG (modulatory proctolin neuron, MPN). Each MCN1 and MCN5 projects through the inferior oesophageal nerve (ion) and stomatogastric nerve (stn) to innervate the STG (Coleman and Nusbaum, 1994; Norris et al., 1996) (Fig. 1). Each CPN2 and MCN7 projects through the superior oesophageal nerve (son) and stn to reach the STG (Norris et al., 1994; Blitz et al., 1999). Each MPN projects through both sons to innervate each CoG and through the stn to gain access to the STG (Nusbaum and Marder, 1989a; Blitz and Nusbaum, 1997) (Fig. 1). In some experiments CPN2 activity was recorded via an intracellular recording of its stomatogastric nerve axon (SNAX) at the entrance to the STG $\left(\mathrm{CPN} 2_{\text {SNAX }}\right)$. CPN2 $2_{\text {SNAX }}$ was identified on the basis of its postsynaptic actions on STG circuit neurons (Norris et al., 1994; Beenhakker and Nusbaum, 2004).

Stimulation parameters. In all experiments a single GPR was activated selectively by extracellular stimulation of either the medial gastric nerve ( $m g n$, GPR1) or the gastropyloric nerve ( $g p n$, GPR2) (Katz et al., 1989), using a Grass S88 stimulator and Grass stimulus isolation unit (SIU5, Astro-Med, West Warwick, RI). Both GPRs had comparable actions in all experiments, so data from them were pooled. In semi-intact preparations GPR activity is time locked to the retractor phase of the gastric mill rhythm (Katz and Harris-Warrick, 1989; Katz et al., 1989). Therefore, in most experiments we stimulated GPR in the isolated stomatogastric system in a gastric mill-like pattern. Previously recorded gastric mill rhythms in the crab exhibited cycle periods that ranged between 8 and 20 sec (Powers, 1973; Selverston and Moulins, 1987; Coleman and Nusbaum, 1994; Norris et al., 1994; Beenhakker et al., 2004). Therefore, GPR was stimulated rhythmically to reflect this range of periods. GPR $1 / 2$ often are activated at relatively low firing frequencies $(<10 \mathrm{~Hz})$ in response to stretch of the gastric mill muscles they innervate (Katz and HarrisWarrick, 1989; Katz et al., 1989; Birmingham et al., 1999). Therefore, we used a steady intraburst stimulus rate $(5 \mathrm{~Hz})$ that was within its previously reported range. The stimulus duration that was used for each GPR stimulus $(4 \mathrm{sec})$ reflected the previously described gastric mill-timed burst duration of the motor neuron (dorsal gastric, DG) that causes the GPR-innervated muscles to stretch (Katz et al., 1989; Birmingham et al., 1999; Beenhakker et al., 2004). Thus the standard GPR stimulation parameters used in this study included burst durations of $4 \mathrm{sec}$, an intraburst firing frequency of $5 \mathrm{~Hz}$, and a cycle period range of 8-50 sec. Where noted, we also used tonic GPR stimulation $(5 \mathrm{~Hz})$.

Data analysis. One gastric mill cycle was defined as beginning and ending with the onset of consecutive lateral gastric (LG) neuron action potential bursts, as is standard in this system (Beenhakker and Nusbaum, 2004; Wood et al., 2004). The burst duration was defined as the duration (sec) between the onset of the first and last action potential within an impulse burst, and the intraburst firing rate of a neuron was defined as the number of action potentials minus one, divided by the burst duration. The cycle period of each gastric mill rhythm was measured as the duration (sec) between the onsets of two successive LG neuron bursts. During a gastric mill rhythm the burst relationships among gastric mill neurons were expressed in terms of phase (i.e., the percentage of a normalized gastric mill cycle during which a neuron is active). Thus phase relationships among gastric mill neurons were determined relative to a 


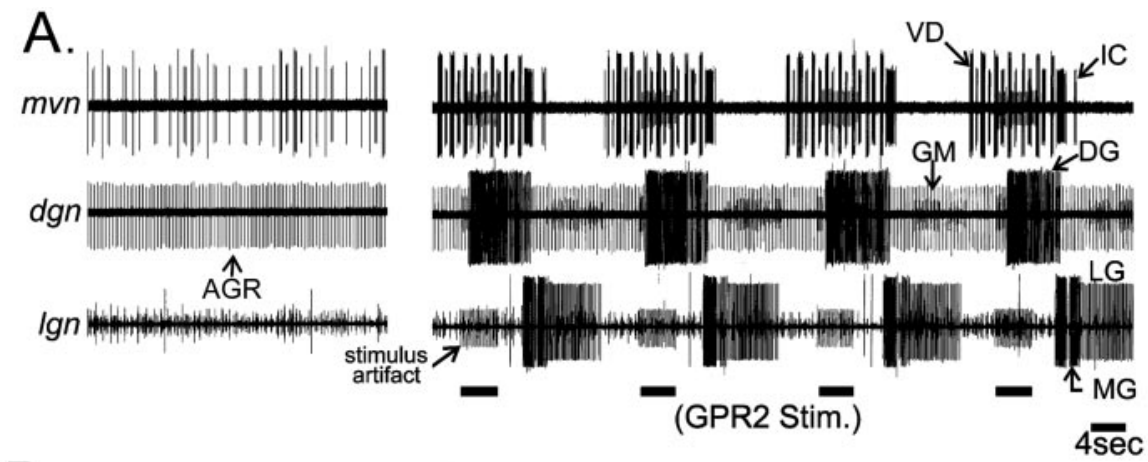

B.

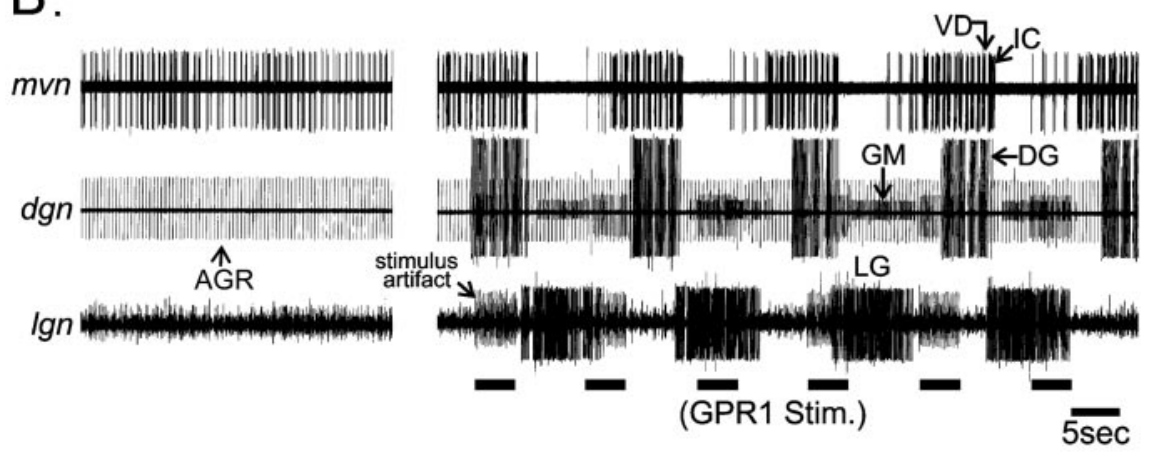

Figure 2. Rhythmic GPR stimulation elicits the gastric mill rhythm. Extracellular recordings of STG nerves were used to monitor the pyloric (mvn) and gastric mill rhythms (Ign, dgn, mvn). A, Left, Before rhythmic GPR stimulation, there was no gastric mill rhythm, but there was a weak pyloric rhythm. $A$, Right, During rhythmic GPR stimulation (black bars), a gastric mill rhythm was elicited, as is evident from the rhythmic alternating bursting in the DG and LG/GM neurons and the gastric mill-timed inhibition of the IC and VD neurons. Note that this gastric mill rhythm was entrained to the GPR stimulations. In both panels, the tonically active unit (dgn) represents the activity of the AGR neuron, a muscle tendon proprioceptor neuron that fires tonically in the isolated STNS (Combes et al., 1995). B, Rhythmic GPR stimulation elicited, but did not entrain, the gastric mill rhythm. $A$ and $B$ are from different preparations.

gastric mill cycle as defined by the onset of one LG neuron burst (beginning of the cycle) and the onset of the subsequent LG neuron burst (end of the cycle). We compared the gastric mill rhythm elicited by GPR stimulation with those elicited by stimulation of the VCNs, using the data set for the latter rhythm that was reported in Beenhakker and Nusbaum (2004).

Data were collected on chart recorder (Astro-Med MT-95000), videotape (Vetter Instruments, Rebersburg, PA), and computer. Acquisition onto computer used the SPIKE2 data acquisition and analysis system (Cambridge Electronic Design, Cambridge, UK). Some data analyses, including neuron burst duration, number of action potentials per burst, intraburst firing frequency, and neuron phase relationships, were conducted on the digitized data with a custom-written SPIKE2 program called "The Crab Analyzer" (freely available at http://www.neurobiologie. $\mathrm{de} /$ ) (Beenhakker and Nusbaum, 2004). Figures were made by scanning data with an HP ScanJet IIC, using DeskScan II (version 2.00a) software. Data were plotted with Excel (version 2002, Microsoft, Redmond, WA) and Prism (version 3.0, GraphPad, San Diego, CA). Final figures were produced by using CorelDraw (version 10.0 for Windows), PowerPoint (version 2002, Microsoft), and Photoshop (version 7.0, Adobe, San Jose, CA). Data are expressed as the mean \pm SD. Nonparametric statistical analyses (Wilcoxon signed rank test and Kruskal-Wallis) were performed with SigmaStat 3.0 (SPSS, Chicago, IL).

\section{Results}

In C. borealis, eliminating projection neuron input to the STG by removing the CoGs terminates any gastric mill circuit activity and causes the pyloric rhythm to weaken or terminate (Beenhakker and Nusbaum, 2004; Wood et al., 2004). In such preparations rhythmic or tonic GPR stimulation excites and modulates the pyloric rhythm and influences some gastric mill neurons, but it does not activate the gastric mill rhythm (Katz and Harris-Warrick, 1989, 1990, 1991). Here we examined the influence of GPR in preparations in which the CoGs remained connected to the STG. In these preparations there is a relatively strong and fast spontaneously active pyloric rhythm and occasionally an ongoing gastric mill rhythm in the absence of GPR stimulation (Beenhakker et al., 2004; Wood et al., 2004). In the experiments that are reported below, our control conditions included only preparations in which there was not a spontaneously active gastric mill rhythm.

\section{GPR stimulation elicits the gastric mill rhythm}

We first tested the ability of tonic GPR stimulation to elicit the gastric mill rhythm. Sustained tonic GPR stimulation $(5 \mathrm{~Hz})$ did elicit the gastric mill rhythm in 7 of 17 preparations. In the other 10 preparations either tonic stimulation did not elicit the gastric mill rhythm, or it elicited only two to five gastric mill cycles. The gastric mill rhythm elicited by tonic GPR stimulation appeared to be comparable with that elicited by stimulating either the VCN mechanosensory system or the inferior ventricular neuron (IVN) projection neurons (Beenhakker and Nusbaum, 2004; Christie et al., 2004). The basic pattern occurring during these gastric mill rhythms included coactivity of the LG, medial gastric (MG), and gastric mill (GM) neurons that alternated with the bursts of interneuron 1 (Int) and the DG, anterior median (AM), inferior cardiac (IC), and ventricular dilator (VD) neurons (data not shown). The ability of tonic GPR stimulation to sometimes elicit the gastric mill rhythm suggested that it did so via modulatory actions (see below), but its unreliability and the fact that it did not reflect accurately the behaviorally relevant GPR activity pattern led us to switch to rhythmic GPR stimulation.

Gastric mill-timed GPR stimulation is the most behaviorally appropriate means of stimulation (Katz et al., 1989). This mode of stimulation, in preparations in which the CoGs remained connected to the STG, was considerably more reliable in eliciting gastric mill rhythms than was tonic GPR stimulation $(n=37$ of 37). The resulting gastric mill rhythm was similar to that elicited by tonic GPR stimulation, including the occurrence of coordinated bursts in the protractor phase neurons (LG, MG, and GM neurons) that alternated with bursts in the coactive retractor phase neurons (Int1, DG, IC, and VD neurons) (Fig. 2). The relatively brief rhythmic and alternating bursts of the IC and VD neurons reflected their pyloric rhythm-timed activity. The pyloric rhythm (cycle period, $\sim 1 \mathrm{sec}$ ) is considerably faster than the gastric mill rhythm (cycle period, $\sim 10-20 \mathrm{sec}$ ) (Beenhakker et al., 2004). In C. borealis several STG neurons including IC and VD exhibit both pyloric and gastric mill-timed activity (Weimann et al., 1991).

The cycle period of the GPR-elicited gastric mill rhythm was entrained to the period of GPR stimulation within a limited 


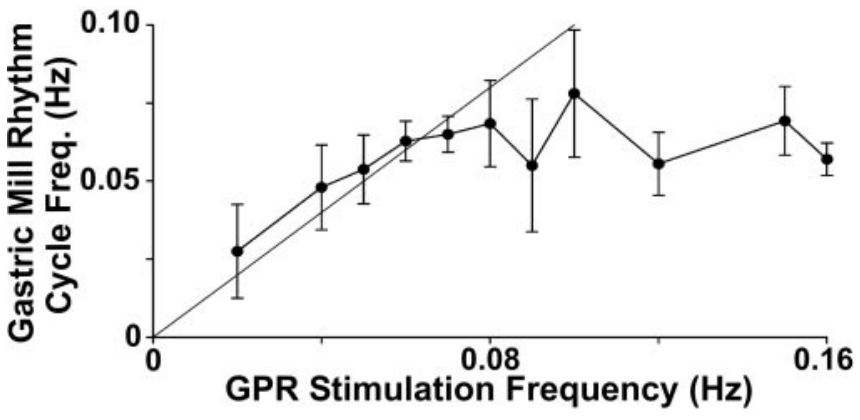

Figure 3. Rhythmic GPR stimulation entrains the gastric mill rhythm over a limited range of stimulation frequencies. The cycle frequency of each GPR-elicited gastric mill rhythm is plotted as a function of the frequency of the corresponding rhythmic GPR stimulation. The straight line represents perfect entrainment of the gastric mill rhythm to the stimulation frequency $(n=$ 3-11 per stimulation frequency). Error bars represent SD.

range. For example, the gastric mill rhythm elicited in Figure $2 \mathrm{~A}$ was entrained to the GPR stimulation period, but this was not the case for the rhythm in Figure $2 \mathrm{~B}$. Specifically, we found that the gastric mill cycle period was entrained when the GPR stimulation cycle period was $>14 \mathrm{sec}$ (cycle frequency, $\leq 0.07 \mathrm{~Hz} ; n=3-11$ preparations per stimulation frequency) (Fig. 3). Briefer cycle periods $(6-12 \mathrm{sec}$; cycle frequency, $0.08-0.16 \mathrm{~Hz}$ ) were equally effective at eliciting the gastric mill rhythm, but the resulting rhythm was not entrained to the stimulation pattern $(n=3-11$ preparations per stimulation frequency) (Figs. $2 B, 3$ ). This range of briefer cycle period stimulations, during which GPR did not entrain the gastric mill rhythm, elicited rhythms with reasonably consistent cycle periods of $16.6 \pm 2.1 \mathrm{sec}$ (cycle frequency, $0.06 \pm$ $0.01 \mathrm{~Hz}$ ). After rhythmic GPR stimulation the gastric mill rhythm persisted for up to $5 \mathrm{~min}$. When a gastric mill rhythm continued poststimulation, it was always qualitatively the same type of rhythm as that which occurred during GPR stimulation.

\section{GPR actions on CoG projection neurons}

Gastric mill rhythms are driven by input from CoG projection neurons, so we next determined whether GPR stimulation influenced any of the four identified CoG projection neurons. GPR stimulation indeed did excite each of these projection neurons. Specifically, GPR stimulation caused a relatively strong excitation of MCN1 and CPN2 and a relatively weak excitation of MCN5 and MCN7 (Fig. 4). Short duration (2-4 sec) GPR stimulation reliably depolarized MCN1 $(n=17$ of 17$)$ and CPN2 $(n=29$ of 29) and elicited a strong burst of action potentials in these neurons (Fig. $4 A, B$ ). In contrast, GPR stimulation elicited a weaker and less consistent activation of MCN5 ( $n=21$ of 26) (Fig. 4C). Although the GPR action on MCN7 was consistent ( $n=7$ of 7 ), it was weaker than that on MCN5 (Fig. 4D). During its period of highest activity the mean MCN1 firing frequency in response to GPR stimulation was $15.2 \pm 7.1 \mathrm{~Hz}(n=8)$, whereas it was $23.1 \pm$ $9.3 \mathrm{~Hz}(n=13)$ for CPN2. MCN5 consistently exhibited a lower firing frequency $(8.8 \pm 11.6 \mathrm{~Hz})$ in response to these GPR stimulations $(n=8)$, and the MCN7 response to GPR stimulation was even weaker $(1.6 \pm 0.3 \mathrm{~Hz} ; n=3)$. It is noteworthy that the MCN5 and MCN7 response to GPR activation was below the activity level at which MCN5 $(>20 \mathrm{~Hz})$ and MCN7 $(>15 \mathrm{~Hz})$ have a major impact on the STG circuits (Norris et al., 1996; Blitz et al., 1999).

We also examined whether GPR stimulation influenced the MPN, a paired projection neuron with somata in the OG and projections to the STG and both CoGs (Nusbaum and Marder,

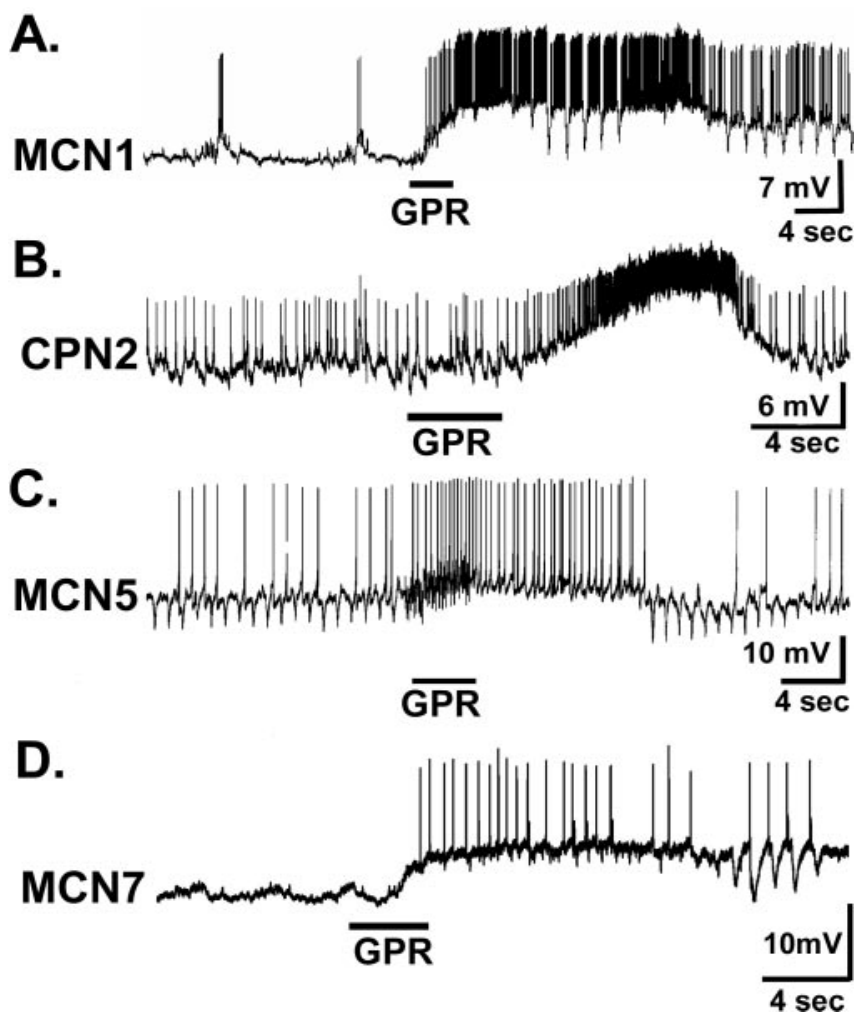

Figure 4. GPR excites all four identified CoG projection neurons. A brief GPR stimulation (black bar) excited all four of these projection neurons, albeit to different extents. Note that in each case, the increased firing of the projection neuron persisted for at least several seconds after the period of stimulation. Each recording was from a different preparation. Most hyperpolarized $V_{\mathrm{m}}$ : MCN1, $-62 \mathrm{mV}$; CPN2, $-56 \mathrm{mV}$; MCN5, $-60 \mathrm{mV}$; MCN7, $-70 \mathrm{mV}$.

1989a,b; Blitz and Nusbaum, 1997). In six of seven preparations GPR stimulation had no effect on MPN. In one preparation GPR stimulation caused a weak activation of MPN (data not shown).

In addition to individual brief GPR stimulations, we examined the influence of rhythmic GPR stimulation on MCN1 $(n=$ $21)$ and $\mathrm{CPN} 2(n=10)$. In the example preparation shown in Figure $5 A, \mathrm{MCN} 1$ was spontaneously active in control conditions, although it was not sufficiently active to elicit the gastric mill rhythm [note the lack of rhythmic bursting in the dorsal gastric nerve $(d g n)$ and lateral gastric nerve ( $\lg n)$ recordings]. Rhythmic GPR stimulation increased ongoing MCN1 activity and elicited the gastric mill rhythm, during which MCN1 activity was time locked to the ongoing rhythm (Fig. 5A). Rhythmic GPR stimulation routinely evoked a comparable and parallel activation of CPN2 and the gastric mill rhythm. For example, in a different preparation from that shown in Figure $5 A$, in which CPN2 was not active and there was no gastric mill rhythm, rhythmic GPR stimulation activated CPN2 and elicited the gastric mill rhythm (Fig. 5B). The intraburst firing frequency exhibited by both MCN1 $(13.8 \pm 4.1 ; n=7)$ and CPN2 $(26.6 \pm 6.2 ; n=4)$ during these GPR-elicited gastric mill rhythms was comparable with their individual responses to single GPR stimulations (see above). The more complex activity pattern exhibited by MCN1 and CPN2 and the variable latency from each GPR stimulation to their increased activity resulted from the additional feedback they received at these times from the gastric mill and pyloric circuits (Coleman and Nusbaum, 1994; Norris et al., 1994). During higher cycle frequency GPR stimulation $(\geq 0.08 \mathrm{~Hz})$, neither MCN1 nor CPN2 was time locked to the GPR stimulation, but 


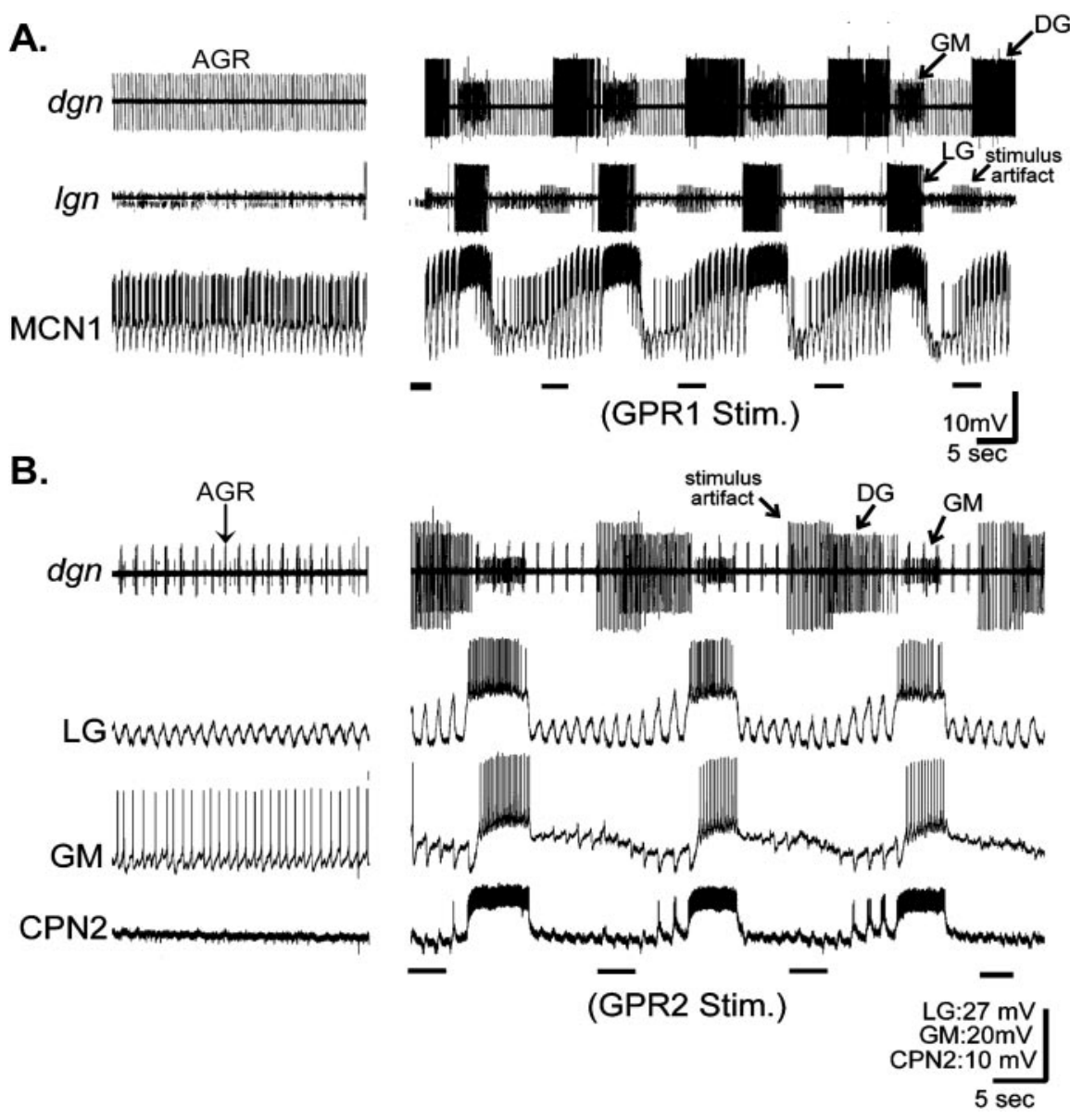

Figure 5. MCN1 and CPN2 are excited and exhibit gastric mill-timed activity during the GPR-elicited gastric mill rhythm. $A$, Left, Before GPR stimulation, there was no gastric mill rhythm, but MCN1 was weakly active. A, Right, During GPR stimulation (black bars), the gastric mill rhythm occurred, and MCN1 activity was strengthened and became gastric mill timed. Most hyperpolarized $V_{\mathrm{m}}: \mathrm{MCN1},-60 \mathrm{mV}$. B, In a different preparation, GPR stimulation elicited the gastric mill rhythm (dgn, LG, GM) and coordinately activated CPN2 to burst in time with this rhythm. Most hyperpolarized $V_{\mathrm{m}}$ : CPN2, $-68 \mathrm{mV} ; \mathrm{GM},-64 \mathrm{mV} ; \mathrm{LG},-78 \mathrm{mV}$.

the activity of each remained gastric mill-timed because of the aforementioned feedback each receives from STG interneurons.

\section{GPR elicits the gastric mill rhythm via its selective activation of MCN1 and CPN2}

Spontaneously occurring MCN1/CPN2-elicited gastric mill rhythms are inhibited by the projection neuron MPN (Blitz and Nusbaum, 1997). MPN inhibits these gastric mill rhythms via its inhibitory actions on MCN1 and CPN2 in the CoGs (Blitz and Nusbaum, 1997, 1999). Therefore, to test the hypothesis that GPR stimulation was activating the gastric mill rhythm via its activation of MCN1 and CPN2, we determined whether MPN stimulation could suppress the GPR-elicited gastric mill rhythm. MPN stimulation indeed did suppress the GPR-elicited gastric mill rhythm routinely despite ongoing GPR stimulation $(n=5)$ (Fig. 6). MPN stimulation (duration, 2-14 sec) during rhythmic GPR stimulation also consistently inhibited MCN1 (Fig. 6) and CPN2 activity (data not shown) while causing a prolonged but reversible cessation of the GPR-elicited gastric mill rhythm $(n=$ 5). Although CPN2 was not recorded directly in the experiment shown in Figure 6, reduction or termination of its activity in response to MPN stimulation was evident from the elimination of GM neuron activity. The GM neurons are a reliable monitor of CPN2 activity because CPN2 is the major excitatory drive to these neurons (Norris et al., 1994), direct suppression of CPN2 during the gastric mill rhythm eliminates GM activity (Beenhakker and Nusbaum, 2004), and MPN has no direct synaptic action on the GM neurons (Blitz and Nusbaum, 1997). After MPN stimulation MCN1 and CPN2 activity gradually returned to preMPN stimulation levels and, when this occurred, the gastric mill rhythm resumed (within $28-113 \mathrm{sec} ; n=5$ ) (Fig. 6). These results supported the hypothesis that GPR elicited the gastric mill rhythm via its activation of MCN1 and CPN2.

To test more directly whether the GPR activation of the gastric mill rhythm was attributable mostly or entirely to its activation of MCN1 and CPN2, we selectively eliminated the influence of these two projection neurons in the STG and again stimulated GPR. To simplify the experiment, we eliminated the influence of one CoG by transecting the son and ion through which it communicated with the STG (Fig. 7). We used an extracellular recording of the ion from the still-connected CoG to monitor the activity of the remaining MCN1. Activity of the remaining CPN2 was monitored with an intracellular recording of its stn axon at the entrance to the STG (Fig. $7)$. In these preparations $(n=8)$ rhythmic GPR stimulation activated MCN1 and CPN2 in the remaining $\mathrm{CoG}$ and elicited the gastric mill rhythm (Fig. 7A).

After these control stimulations we selectively eliminated the activity of MCN1 and CPN2 (Beenhakker and Nusbaum, 2004). To suppress MCN1 activity, we took advantage of the fact that its axon projects through the ion to innervate the STG (Coleman and Nusbaum, 1994). Therefore, we reversibly blocked MCN1 action potential propagation toward the STG by replacing the saline within a Vaseline well surrounding a portion of the desheathed ion with an isotonic $(750 \mathrm{mM})$ sucrose solution (Fig. $7 B$ ). In a subset of experiments MCN1 action potential propagation instead was blocked irreversibly by transecting the ion. MCN5 is the only other projection neuron that projects through the ion to reach the STG (Coleman et al., 1992; Norris et al., 1996), and, as reported above, MCN5 is not activated sufficiently by GPR stimulation to influence the STG circuits. We selectively eliminated the influence of CPN2 within the STG by injecting hyperpolarizing current into its $\operatorname{stn}$ axon (Fig. 7B). With sufficient hyperpolarization these action potentials failed to propagate actively into the STG. The propagation failure was documented by the loss of CPN2-mediated EPSPs into its previously identified postsynaptic target, the GM neuron (Fig. 7B) (Norris et al., 1994; Beenhakker and Nusbaum, 2004).

Eliminating the influence of both MCN1 and CPN2 in the STG prevented GPR stimulation from activating the gastric mill rhythm ( $n=5$ of 5 sucrose block; $n=3$ of 3 ion-transected) (Fig. $7 B$ ). It was clear that at these times GPR stimulation still excited MCN1 and CPN2 in the CoG. MCN1 activation was evident from the ion recording (on the CoG side of the ion transection/sucrose block) (Fig. 7B). CPN2 activation was recorded via the intraaxonal recording through which it was hyperpolarized. Despite 


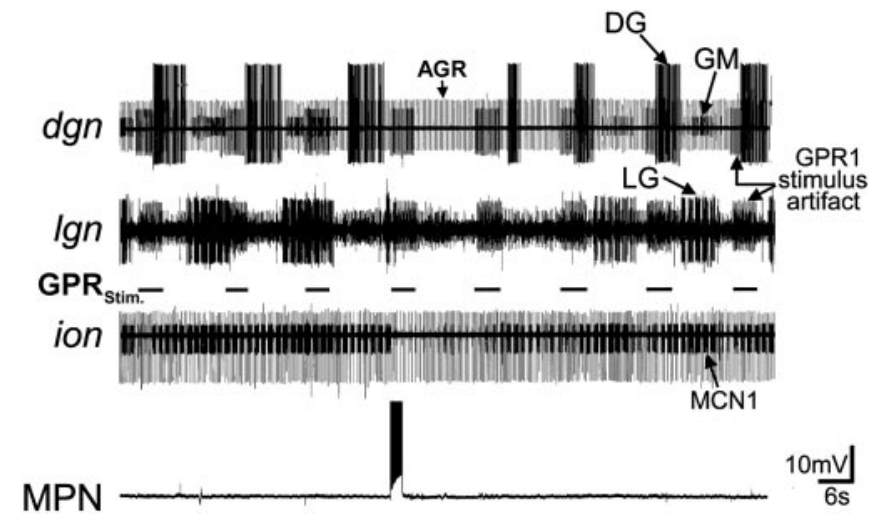

Figure 6. Stimulation of the MPN projection neuron reversibly suppressed the GPR-elicited gastric mill rhythm as well as MCN1 activity. MCN1 activity was monitored with an extracellular recording (ion) (Coleman and Nusbaum, 1994). The rhythmic GPR stimulation excited MCN1 and CPN2 (data not shown) and elicited the gastric mill rhythm (dgn, Ign). Brief (2 sec) MPN stimulation reversibly inhibited MCN1 and CPN2 and suppressed the gastric mill rhythm. MCN1 and CPN2 activity as well as the gastric mill rhythm resumed $\sim 10$ sec after the end of the MPN stimulation. Rhythmic GPR stimulation began before the start of the panel.

the GPR-mediated increase in CPN2 activity, its action potentials did not reach the STG because of the hyperpolarizing current injection (Fig. $7 B$ ). It was also clear that the extracellular GPR stimulations still effectively activated this sensory neuron, because the DG neuron continued to exhibit rhythmic bursts of activity caused by its direct excitation by GPR within the STG (Katz and Harris-Warrick, 1989; Kiehn and Harris-Warrick, 1992). Eliminating the CPN2 excitation of the GM neuron also made the DG neuron inhibition of GM more evident (Fig. 7B). The block of the activation of the gastric mill rhythm by GPR stimulation was reversible in three sucrose block preparations in which we were able to maintain the recordings for a sufficient duration (data not shown). Thus, GPR stimulation requires the influence of the projection neurons MCN1 and CPN2 to elicit the gastric mill rhythm.

\section{Quantification of the GPR-elicited gastric mill rhythm}

Our results demonstrating that the GPR sensory neurons elicit the gastric mill rhythm via excitation of the MCN1 and CPN2 projection neurons motivated us to compare the GPR-elicited rhythm with another previously characterized gastric mill rhythm that also operates via MCN1 and CPN2. To this end, we first quantified several aspects of the GPR-elicited gastric mill rhythm by using a standard rhythmic GPR stimulation protocol (cycle frequency, $0.06 \mathrm{~Hz}$; stimulation duration, $4 \mathrm{sec}$; intraburst frequency, $5 \mathrm{~Hz}$ ). This protocol includes a cycle frequency that is well within the previously recorded range of gastric mill frequencies in the crab both in vitro and in vivo (Powers, 1973; Selverston and Moulins, 1987; Heinzel et al., 1993; Coleman and Nusbaum, 1994; Norris et al., 1994; Beenhakker et al., 2004).

The LG and DG neurons had similar activity levels during the GPR-elicited gastric mill rhythm. The LG neuron fired $76.4 \pm 36$ action potentials/burst (intraburst firing frequency, $12.5 \pm 6 \mathrm{~Hz}$ ) in a burst that lasted $6.0 \pm 1.4 \mathrm{sec}(n=15)$ (Fig. $8 A-C)$. The DG neuron fired $65.7 \pm 28$ action potentials/burst (intraburst firing frequency, $11.8 \pm 5 \mathrm{~Hz}$ ) with a mean burst duration of $5.6 \pm 1.6$ $\sec (n=8)$ (Fig. $8 A-C)$. The MG neuron fired the shortest duration burst $(1.8 \pm 1.6 \mathrm{sec})$, which consisted of $26.7 \pm 20$ action potentials (firing frequency, $14.5 \pm 4 \mathrm{~Hz} ; n=5$ ) (Fig. $8 A-C$ ). The collective burst duration of the four GM neurons was $5.6 \pm 1.1$ $\sec (n=10)$. Finally, we characterized the gastric mill-timed activity patterns of the IC and VD neurons. We grouped together their gastric mill-related activity because they were coactive during the LG neuron interburst and their activity coterminated during each LG neuron burst. The bursting activity of both neurons (IC, VD) during a gastric mill cycle lasted $10.1 \pm 3.0 \mathrm{sec}(n=8)$.

We also performed a phase analysis to determine the burst relationship among the gastric mill neurons during the GPRelicited gastric mill rhythm. As is standard for this rhythm, we defined one gastric mill cycle as beginning and ending with the onset of consecutive LG neuron action potential bursts (Beenhakker and Nusbaum, 2004; Wood et al., 2004). As illustrated in Figure $8 D$, the coactive LG $(n=16)$ and GM $(n=10)$ neurons were active for $\sim 43$ and $38 \%$, respectively, of each gastric mill cycle. The start of the GM neuron burst was delayed relative to the LG neuron burst onset by $\sim 7.4 \%$ of the gastric mill cycle. MG neuron activity started early in the cycle and terminated $\sim 17 \%$ into the cycle $(n=5)$. DG neuron activity showed little overlap with the LG and GM bursts and was active for $\sim 40 \%$ of each gastric cycle $(n=8)$. IC and VD fired during the latter $75 \%$ of each gastric cycle ( $n=8$; data not shown).

\section{Comparison of the GPR-elicited and VCN-elicited gastric mill rhythms}

The gastric mill circuit can produce several versions of the gastric mill rhythm (Bartos et al., 1999; Beenhakker and Nusbaum, 2004; Wood et al., 2004). These rhythms are characterized by differences in the timing and strength of activity in the gastric mill circuit neurons. Because the GPR pathway (this work) and the previously characterized VCN mechanosensory pathway (Beenhakker and Nusbaum, 2004) both target MCN1 and CPN2 to generate their respective gastric mill rhythms, we compared several parameters between these two rhythms. We used the GPRelicited rhythm parameters reported in the preceding section and VCN data from Beenhakker and Nusbaum (2004) (Fig. 8). As shown in Figure 8, there were both similarities and differences between these two versions of the gastric mill rhythm. For example, the burst durations of the LG (VCN, $5.4 \pm 2.3 \mathrm{sec} ; n=16$ ) and MG (VCN, $1.2 \pm 0.6 \mathrm{sec} ; n=9)$ neurons were comparable during these two rhythms $(p>0.05)$ (Fig. $8 A$ ). The burst duration of the DG neuron, however, was $~ 30 \%$ longer during GPR stimulation than during VCN stimulation (VCN, $3.8 \pm 1.0 \mathrm{sec}$; $n=13 ; p<0.01$ ) (Fig. $8 \mathrm{~A}$ ).

The number of action potentials ("spikes") generated during each burst discharge in the LG, MG, and DG neurons was larger during the GPR-elicited rhythm (Fig. $8 \mathrm{~B}$ ). Specifically, during the VCN-elicited rhythm the LG neuron fired nearly $50 \%$ fewer spikes per burst $(44.8 \pm 16.1 ; n=16 ; p<0.01)$, the MG neuron fired $\sim 30 \%$ fewer spikes per burst $(8.9 \pm 4.4 ; n=9 ; p<0.05)$, and the DG neuron fired $\sim 50 \%$ fewer spikes per burst $(31.5 \pm$ $11.5 ; n=13 ; p<0.01)$. Two of these three gastric mill neurons also showed a faster firing rate during the GPR-elicited rhythm. This included the intraburst firing frequency of the LG neuron, which was $\sim 30 \%$ faster in the GPR-elicited rhythm (VCN, $8.5 \pm$ $1.9 \mathrm{~Hz} ; n=16 ; p<0.05)$, and the MG neuron, which was $\sim 40 \%$ faster (VCN, $7.9 \pm 2.8 \mathrm{~Hz} ; n=9 ; p<0.05$ ) (Fig. 8C). The intraburst firing frequency of the DG neuron was comparable during the GPR-elicited and the VCN-elicited rhythms (VCN, $8.3 \pm 2.9 \mathrm{~Hz} ; n=13 ; p>0.05$ ) (Fig. $8 C$ ).

The cycle period of the GPR-elicited gastric mill rhythm $(15.3 \pm 5.3 \mathrm{sec} ; n=15)$ was nearly $40 \%$ longer than that of the VCN-elicited rhythm $(10.8 \pm 2.3 \mathrm{sec} ; n=16 ; p<0.01)$. This difference was not attributable to the GPR stimulus parameters used in our protocol because there was little overlap between the 


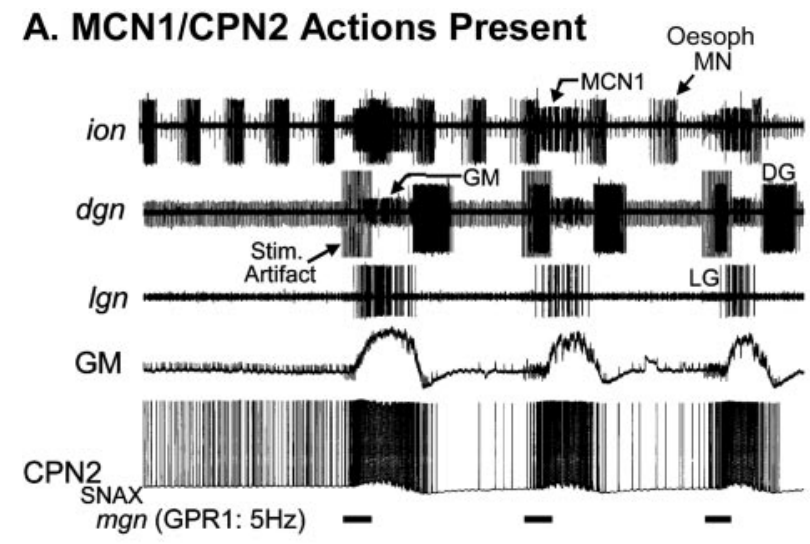

B. MCN1/CPN2 Actions Blocked

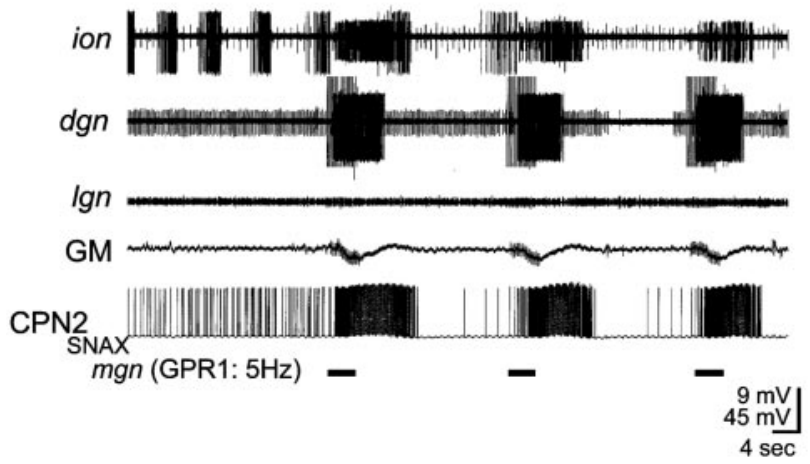

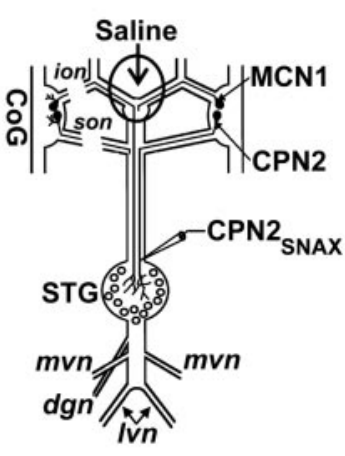

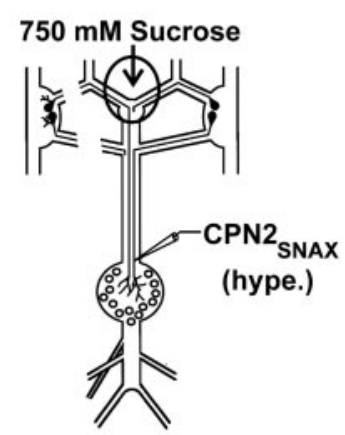

Figure 7. The actions of MCN1 and CPN2 in the STG are necessary for GPR activation of the gastric mill rhythm. MCN1 activity was monitored with an extracellular recording (ion), and CPN2 activity was monitored and manipulated with an intracellular recording of its stn axon (CPN2 $2_{\text {SNAX }}$ ) near the STG. A, Left, Rhythmic GPR stimulation (black bars) activated MCN1 and CPN2 and elicited the gastric mill rhythm (dgn, Ign, GM). The large-amplitude rhythmic bursts in the ion represent the activity of an oesophageal motor neuron (0esoph MN) during an ongoing oesophageal rhythm, which is generated in the CoGs. A, Right, Schematic of the experimental setup. Most hyperpolarized $V_{\mathrm{m}}: \mathrm{CPN}_{\mathrm{SNAx}},-49 \mathrm{mV} ; G M,-73 \mathrm{mV}$. B, Selectively eliminating access to the STG for MCN1 and CPN2 prevented GPR activation of the gastric mill rhythm (dgn, Ign, GM). Rhythmic DG bursting persisted because of the direct excitatory action of GPR on the DG neuron (Katz and Harris-Warrick, 1989). Most hyperpolarized $V_{\mathrm{m}}: G M,-73$

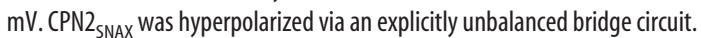

A.

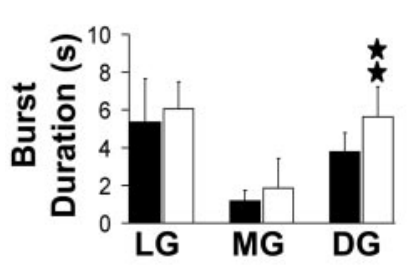

C.

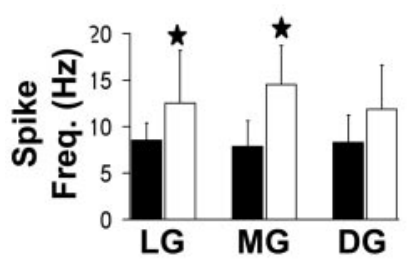

B.

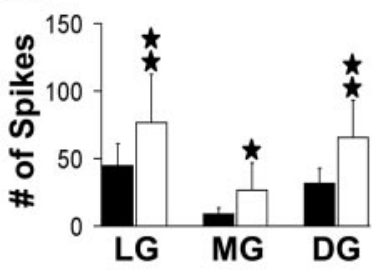

D.

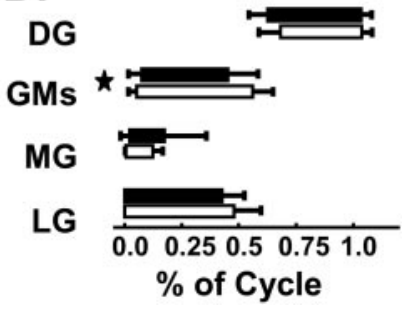

Figure 8. Comparison of the GPR-elicited and VCN-elicited gastric mill rhythms. The burst duration, number of action potentials, intraburst firing frequencies, and phase relationships of gastric mill circuit neurons are plotted for GPR-elicited (white bars) and VCN-elicited (black bars) rhythms. Nonparametric Mann-Whitney rank sum test was performed to compare these data; ${ }^{*} p<0.05$; ${ }^{* *} p<$ 0.01. VCN data from Beenhakker and Nusbaum (2004). Error bars represent SD.

fastest GPR-elicited rhythms and the slowest VCN-elicited rhythms. Furthermore, the cycle period of the VCN-elicited gastric mill rhythm is not a function of the VCN stimulus parameters. Specifically, the gastric mill cycle period was the same regardless of whether VCN stimulation was tonic, pyloric-like, or rhythmic in a manner that was comparable with that used for GPR stimulation (Beenhakker et al., 2004).

Most aspects of the relative burst patterns of the gastric mill neurons during the normalized gastric mill rhythms (phase relationships) were comparable during the GPR-elicited and VCN-elicited rhythms (Fig. $8 D$ ). Naturally, because it designates the start of each cycle, the burst onset of the LG neuron was always zero during the phase analysis of both rhythms (VCN, $n=$ 16; GPR, $n=15$ ). The burst onset phase of the MG (VCN, $0.7 \pm 0.8 \%, n=9$; GPR, $2.2 \pm 3.8 \%, n=5)$ and DG (VCN, $67.9 \pm$ $9.3 \%, n=13$; GPR, $62.5 \pm 8.2 \%, n=8)$ neurons was comparable $(p>0.05)$ during these two rhythms. The same was true for the burst terminations of the LG (VCN, $48.0 \pm 11.8 \%, n=16$; GPR, $42.6 \pm 9.6 \%$, $n=15), \mathrm{MG}(\mathrm{VCN}, 12.5 \pm 4.6 \%, n=9$; GPR, $17.7 \pm 18.4 \%, n=5)$, GM (VCN, $55.8 \pm 8.9 \%, n=13$; GPR, $45.3 \pm 12.7 \%$, $n=10)$, and DG (VCN, $103.8 \pm 4.6 \%, n=$ 13; GPR, $103.4 \pm 4.6 \%, n=8$ ) neurons $(p>0.05)$. The only phase parameter that was significantly different between the two studied conditions was the GM neuron burst onset, which was phase advanced during the GPR-elicited rhythm (VCN, $13.7 \pm 5.9 \%, n=13$; GPR, $7.4 \pm 5.6 \%$, $n=10 ; p<0.05)$. 


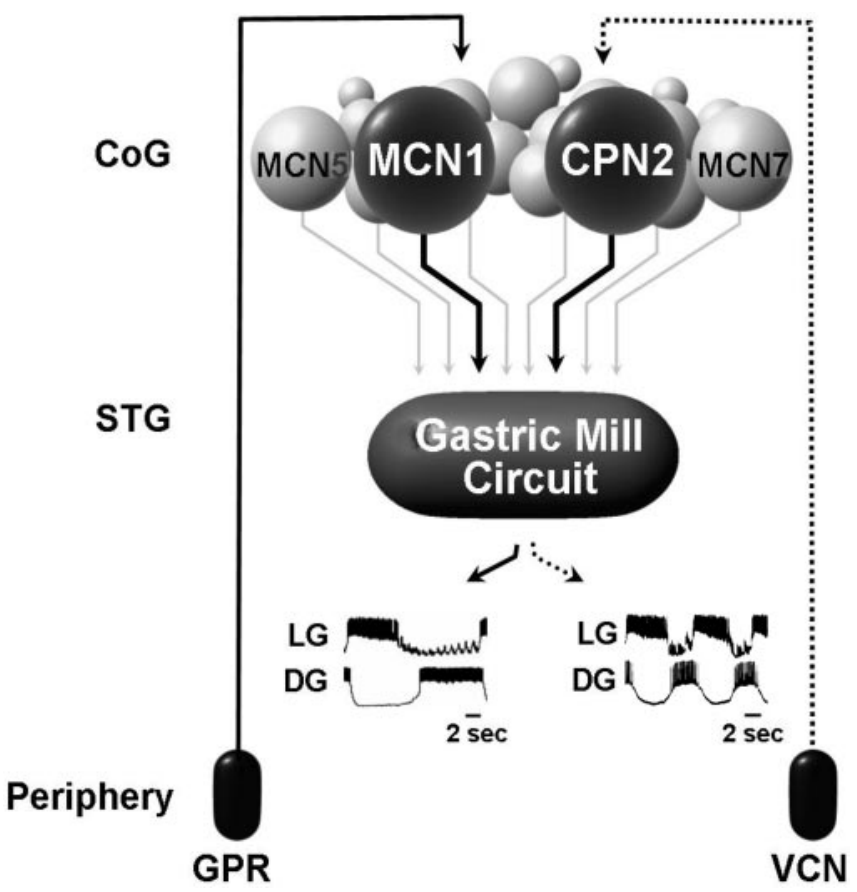

Figure 9. Schematic of the $\mathrm{COG}$ projection neuron targets of the VCN mechanosensory system and the GPR proprioceptor system that enable each sensory system to activate the gastric mill rhythm. Note that, for each sensory system, only the MCN1 and CPN2 projection neurons are necessary to drive the gastric mill rhythm despite the ability of each sensory system to activate at least some of the other $\mathrm{C} O \mathrm{G}$ projection neurons that influence the gastric mill circuit. Despite sharing the coactivation of MCN1 and CPN2, the VCN and GPR systems elicit different versions of the gastric mill rhythm. For example, as is evident in the gastric mill recordings, the GPR-elicited rhythm is slower than the VCN-elicited rhythm.

tribution of additional projection neurons, (2) differences in the firing frequency of MCN1 and/or CPN2 under these two conditions, and/or (3) the presence of additional synapses onto gastric mill circuit neurons by one or both of these sensory systems.

The first possibility appears to be the least likely to contribute to the different rhythms. For example, although selective suppression of MCN1 and CPN2 input to the STG did not eliminate all GPR influence onto the gastric mill neurons, the persisting actions are likely to result from direct GPR actions onto these neurons (see below). It also seems unlikely that additional projection neurons contribute to the VCN-elicited gastric mill rhythm because MCN1 and CPN2 are not only necessary but probably sufficient for the activation of this rhythm (Beenhakker and Nusbaum, 2004). Both the VCN and GPR sensory systems do activate at least two additional projection neurons (MCN5, MCN7) that influence gastric mill neurons. However, neither the duration nor the strength of these sensory actions is sufficient to enable MCN5 or MCN7 to drive its STG targets effectively (Norris et al., 1996; Blitz et al., 1999; Beenhakker et al., 2004; this work). Nevertheless, there might be additional, as yet unidentified, projection neurons that are activated by GPR and/or VCN to contribute to the resulting gastric mill rhythms.

We did find experimental support for the second possibility in that the MCN1 firing frequency during the GPR-elicited gastric mill rhythm was approximately one-half that occurring during the VCN-elicited rhythm (Beenhakker and Nusbaum, 2004; this work). In contrast, the mean CPN2 firing rate was the same during both of these gastric mill rhythms (Beenhakker and Nusbaum, 2004; this work). Support for the hypothesis that the distinct MCN1 response contributes to these different rhythms comes from the fact that, during direct MCN1 stimulation, increasing the MCN1 firing frequency from the level occurring during GPR stimulation to that occurring during VCN stimulation elicits a faster gastric mill rhythm (Bartos et al., 1999), and the VCN-elicited rhythm is faster than the GPR-elicited rhythm (Beenhakker and Nusbaum, 2004; this work).

There is also support for the third possible mechanism underlying the distinct VCN-elicited and GPR-elicited rhythms because GPR does have strong, direct excitatory actions on several gastric mill neurons, even in the isolated STG (Katz and HarrisWarrick, 1989, 1991; Beenhakker, 2004). These direct actions are comparable with those occurring after selective suppression of MCN1 and CPN2 access to the STG (Beenhakker, 2004; this work). One such GPR action that likely contributes to its distinct gastric mill rhythm is its ability to elicit plateau potentials in the DG neuron (Katz and Harris-Warrick, 1989; Kiehn and HarrisWarrick, 1992). In contrast to these GPR actions, with the CoGs removed there is only a weak and probably indirect VCN influence onto some gastric mill neurons via its direct influence on the pyloric rhythm (Beenhakker et al., 2004). Either or both of these sensory systems also might influence the STG terminals of projection neurons, insofar as the STG terminals of MCN1 and CPN2 are known to receive synaptic feedback from STG neurons (Nusbaum et al., 1992; Coleman and Nusbaum, 1994; Blitz and Nusbaum, 1997). The extent to which these additional pathways contribute to the distinct GPR-elicited and VCN-elicited gastric mill rhythms remains to be determined.

The GPR and VCN sensory systems perform distinct functions. The VCN system is well situated to inform the gastric mill system about the presence of food and to ensure that chewing is initiated and maintained for an extended duration (Beenhakker et al., 2004). In support of this role the gastric mill rhythm persists for tens of minutes after VCN stimulation (Beenhakker et al., 2004). It is not clear under what behavioral conditions the GPR system would be needed to activate the gastric mill rhythm, insofar as these neurons are activated during retraction of the medial tooth as occurs during chewing (Katz and Harris-Warrick, 1989; Katz et al., 1989). One possibility is that the GPRs normally help to ensure that, once activated, chewing persists, albeit with the documented alterations. Given that the GPR-elicited rhythm is slower and includes stronger gastric mill neuron bursts than during the VCN-elicited rhythm, the incorporation of GPR activity likely would change the rhythm to one with a stronger protraction of the lateral teeth and a stronger and longer-lasting retraction of the medial tooth (Heinzel et al., 1993).

Presumably in keeping with its proprioceptive function, brief GPR stimulation activated a single episode of the gastric mill retractor phase, with its actions being sufficiently long-lasting to enable subsequent activation of the protractor phase. When such stimulations were repeated rhythmically and spaced sufficiently far apart, each one elicited a single gastric mill cycle and thereby elicited an entrained gastric mill rhythm, including the coordinated activation of MCN1 and CPN2. This entrainment ability presumably pertains to the classic proprioceptor role of providing fast and relatively short-lasting feedback to a motor circuit in response to an unexpected perturbation, albeit in this case including feedback to the relevant projection neurons (Bracci et al., 1997; Evans and Cropper, 1998; Pearson et al., 1998; Evans et al., 1999; Hess and Buschges, 1999; Cang and Friesen, 2000; Lam and Pearson, 2001; Morin and Viala, 2002; Pearson, 2004).

Sensory neurons also can have longer-lasting modulatory actions (Robertson and Laverack, 1979; Sigvardt and Mulloney, 1982; Weiss et al., 1986a,b; Hooper and Moulins, 1990; Meyrand 
et al., 1994; Rosen et al., 2000; Beenhakker et al., 2004). GPR does have modulatory as well as ionotropic actions in the STG on both gastric mill and pyloric neurons (Katz and Harris-Warrick, 1989, 1990, 1991; Kiehn and Harris-Warrick, 1992). Additionally supporting a modulatory influence of the GPRs, presumably at the level of MCN1 and CPN2, was their ability to drive the gastric mill rhythm without entraining it when it was stimulated at relatively high cycle frequencies. Given the normal range of gastric mill speeds in the intact animal, the GPR neurons appear well suited to play both roles. GPR exhibits comparable entraining and modulating actions on the pyloric rhythm in the STG, but the behavioral role of these dual actions remains to be determined for both of these rhythms (Katz and Harris-Warrick, 1990).

It is also possible to obtain different motor circuit outputs by varying the activity level of a single sensory system. For example, in the stomatogastric system of the European lobster Homarus gammarus the anterior gastric receptor (AGR) sensory neuron elicits two different versions of the gastric mill rhythm when AGR fires at relatively low and high frequencies (Combes et al., 1999a,b). The different rhythms result at least partly from AGR exhibiting different patterns of short-term synaptic plasticity in its excitation of two different projection neurons (Combes et al., 1999a,b). It remains to be determined whether these AGR actions in the lobster system also include additional projection neurons.

The fact that both the GPR and VCN neurons activate the gastric mill rhythm via their excitation of MCN1 and CPN2 supports the hypothesis that sensory neurons code for particular behaviors by influencing a subpopulation of the projection neurons that target a particular neuronal circuit (Kristan and Shaw, 1997; Deliagina et al., 2002). The present work also expands our appreciation for the flexibility available to sensory systems that regulate neuronal circuit activity by highlighting that different sensory systems do not require different projection neuron targets to elicit distinct activity patterns from the same neuronal circuit. Given the presence of $\sim 15$ additional, distinct modulatory projection neurons that innervate the STG (Coleman et al., 1992; Nusbaum et al., 2001; Marder and Thirumalai, 2002), it is unlikely that all sensory influences on the STG circuits converge onto the same pair of projection neurons. Consequently, additional insights are likely to come from continuing to unravel the rules by which distinct sensory systems, activated separately and conjointly, regulate these small motor circuits.

\section{References}

Akay T, Haehn S, Schmitz J, Buschges A (2004) Signals from load sensors underlie interjoint coordination during stepping movements of the stick insect leg. J Neurophysiol 92:42-51.

Bartos M, Nusbaum MP (1997) Intercircuit control of motor pattern modulation by presynaptic inhibition. J Neurosci 17:2247-2256.

Bartos M, Manor Y, Nadim F, Marder E, Nusbaum MP (1999) Coordination of fast and slow rhythmic neuronal circuits. J Neurosci 19:6650-6660.

Beenhakker MP (2004) Sensory regulation of rhythmically active neuronal networks. PhD thesis, University of Pennsylvania.

Beenhakker MP, Nusbaum MP (2004) Mechanosensory activation of a motor circuit by coactivation of two projection neurons. J Neurosci 24:6741-6750.

Beenhakker MP, Blitz DM, Nusbaum MP (2004) Long-lasting activation of rhythmic neuronal activity by a novel mechanosensory system in the crustacean stomatogastric nervous system. J Neurophysiol 91:78-91.

Birmingham JT, Szuts Z, Abbott LF, Marder E (1999) Encoding of muscle movement on two time scales by a sensory neuron that switches between spiking and burst modes. J Neurophysiol 82:2786-2797.

Blitz DM, Nusbaum MP (1996) Sensory neuron activation of modulatory projection neurons. Soc Neurosci Abstr 22:544.1.

Blitz DM, Nusbaum MP (1997) Motor pattern selection via inhibition of parallel pathways. J Neurosci 17:4965-4975.
Blitz DM, Nusbaum MP (1999) Distinct functions for cotransmitters mediating motor pattern selection. J Neurosci 19:6774-6783.

Blitz DM, Christie AE, Coleman MJ, Norris BJ, Marder E, Nusbaum MP (1999) Different proctolin neurons elicit distinct motor patterns from a multifunctional neuronal network. J Neurosci 19:5449-5463.

Borovikov D, Evans CG, Jing J, Rosen SC, Cropper EC (2000) A proprioceptive role for an exteroceptive mechanoafferent neuron in Aplysia. J Neurosci 20:1990-2002.

Bracci E, Beato M, Nistri A (1997) Afferent inputs modulate the activity of a rhythmic burst generator in the rat disinhibited spinal cord in vitro. J Neurophysiol 77:3157-3167.

Cang J, Friesen WO (2000) Sensory modification of leech swimming: rhythmic activity of ventral stretch receptors can change intersegmental phase relationships. J Neurosci 20:7822-7829.

Christie AE, Stein W, Quinlan JE, Beenhakker MP, Marder E, Nusbaum MP (2004) Actions of a histaminergic/peptidergic projection neuron on rhythmic motor patterns in the stomatogastric nervous system of the crab Cancer borealis. J Comp Neurol 469:153-169.

Coleman MJ, Nusbaum MP (1994) Functional consequences of compartmentalization of synaptic input. J Neurosci 14:6544-6552.

Coleman MJ, Nusbaum MP, Cournil I, Claiborne BJ (1992) Distribution of modulatory inputs to the stomatogastric ganglion of the crab, Cancer borealis. J Comp Neurol 325:581-594.

Coleman MJ, Meyrand P, Nusbaum MP (1995) A switch between two modes of synaptic transmission mediated by presynaptic inhibition. Nature 378:502-505.

Combes D, Simmers AJ, Moulins M (1995) Structural and functional characterization of a muscle tendon proprioceptor in lobster. J Comp Neurol 363:221-234.

Combes D, Meyrand P, Simmers J (1999a) Motor pattern specification by dual descending pathways to a lobster rhythm-generating network. J Neurosci 19:3610-3619.

Combes D, Meyrand P, Simmers J (1999b) Dynamic restructuring of a rhythmic motor program by a single mechanoreceptor neuron in lobster. J Neurosci 19:3620-3628.

Deliagina TG, Zelenin PV, Orlovsky GN (2002) Encoding and decoding of reticulospinal commands. Brain Res Rev 40:166-177.

Evans CG, Cropper EC (1998) Proprioceptive input to feeding motor programs in Aplysia. J Neurosci 18:8016-8031.

Evans CG, Alexeeva V, Rybak J, Karhunen T, Weiss KR, Cropper EC (1999) A pair of reciprocally inhibitory histaminergic sensory neurons are activated within the same phase of ingestive motor programs in Aplysia. J Neurosci 19:845-858.

Frost WN, Katz PS (1996) Single neuron control over a complex motor program. Proc Natl Acad Sci USA 93:422-426.

Gahtan E, Sankrithi N, Campos JB, O’Malley DM (2002) Evidence for a widespread brain stem escape network in larval zebrafish. J Neurophysiol 87:608-614.

Heinzel H-G, Weimann JM, Marder E (1993) The behavioral repertoire of the gastric mill in the crab, Cancer pagurus: an in situ endoscopic and electrophysiological examination. J Neurosci 13:1793-1803.

Hess D, Buschges A (1999) Role of proprioceptive signals from an insect femur-tibia joint in patterning motorneuronal activity of an adjacent leg joint. J Neurophysiol 81:1856-1865.

Hooper SL, Moulins M (1990) Cellular and synaptic mechanisms responsible for a long-lasting restructuring of the lobster pyloric network. J Neurophysiol 64:1574-1589.

Hooper SL, Moulins M, Nonnotte L (1990) Sensory input induces longlasting changes in the output of the lobster pyloric network. J Neurophysiol 64:1555-1573.

Katz PS, Harris-Warrick RM (1989) Serotonergic/cholinergic muscle receptor cells in the crab stomatogastric nervous system. II. Rapid nicotinic and prolonged modulatory effects on neurons in the stomatogastric ganglion. J Neurophysiol 62:571-581.

Katz PS, Harris-Warrick RM (1990) Neuromodulation of the crab pyloric central pattern generator by serotonergic/cholinergic proprioceptive afferents. J Neurosci 10:1495-1512.

Katz PS, Harris-Warrick RM (1991) Recruitment of crab gastric mill neurons into the pyloric motor pattern by mechanosensory afferent stimulation. J Neurophysiol 65:1442-1451.

Katz PS, Eigg MH, Harris-Warrick RM (1989) Serotonergic/cholinergic muscle receptor cells in the crab stomatogastric nervous system. I. Iden- 
tification and characterization of the gastropyloric receptor cells. J Neurophysiol 62:558-570.

Kiehn O, Harris-Warrick RM (1992) Serotonergic stretch receptors induce plateau properties in a crustacean motor neuron by a dual-conductance mechanism. J Neurophysiol 68:485-495.

Kristan WB, Shaw BK (1997) Population coding and behavioral choice. Curr Opin Neurobiol 7:826-831.

Lam T, Pearson KG (2001) Proprioceptive modulation of hip flexor activity during the swing phase of locomotion in decerebrate cats. J Neurophysiol 86:1321-1332.

Liu KS, Fetcho JR (1999) Laser ablations reveal functional relationships of segmental hindbrain neurons in zebrafish. Neuron 23:325-335.

Marder E, Thirumalai V (2002) Cellular, synaptic and network effects of neuromodulation. Neural Netw 15:479-493.

Meyrand P, Simmers J, Moulins M (1994) Dynamic construction of a neural network from multiple pattern generators in the lobster stomatogastric nervous system. J Neurosci 14:630-644.

Morin D, Viala D (2002) Coordinations of locomotor and respiratory rhythms in vitro are critically dependent on hindlimb sensory inputs. J Neurosci 22:4756-4765.

Norris BJ, Coleman MJ, Nusbaum MP (1994) Recruitment of a projection neuron determines gastric mill motor pattern selection in the stomatogastric nervous system of the crab, Cancer borealis. J Neurophysiol 72:1451-1463.

Norris BJ, Coleman MJ, Nusbaum MP (1996) Pyloric motor pattern modification by a newly identified projection neuron in the crab stomatogastric nervous system. J Neurophysiol 75:97-108.

Nusbaum MP, Beenhakker MP (2002) A small-systems approach to motor pattern generation. Nature 417:343-350.

Nusbaum MP, Marder E (1989a) A modulatory proctolin-containing neuron (MPN). I. Identification and characterization. J Neurosci 9:1591-1599.

Nusbaum MP, Marder E (1989b) A modulatory proctolin-containing neuron (MPN). II. State-dependent modulation of rhythmic motor activity. J Neurosci 9:1600-1607.

Nusbaum MP, Weimann JM, Golowasch J, Marder E (1992) Presynaptic control of modulatory fibers by their neural network targets. J Neurosci 12:2706-2714.

Nusbaum MP, Blitz DM, Swensen AM, Wood D, Marder E (2001) The roles of co-transmission in neural network modulation. Trends Neurosci 24:146-154.

O’Malley DM, Kao Y-H, Fetcho JR (1996) Imaging the functional organi- zation of zebrafish hindbrain segments during escape behaviors. Neuron 17:1145-1155.

Pearson K (2004) Generating the walking gait: role of sensory feedback. Prog Brain Res 143:123-129.

Pearson K, Misiaszek JE, Fouad K (1998) Enhancement and resetting of locomotor activity by muscle afferents. Ann NY Acad Sci 860:203-215.

Perrins R, Weiss KR (1996) A cerebral central pattern generator in Aplysia and its connections with buccal feeding circuitry. J Neurosci 16:7030-7045.

Perrins R, Walford A, Roberts A (2002) Sensory activation and role of inhibitory reticulospinal neurons that stop swimming in hatchling frog tadpoles. J Neurosci 22:4229-4240.

Pouget A, Dayan P, Zemel RS (2003) Inference and computation with population codes. Annu Rev Neurosci 26:381-410.

Powers LS (1973) Gastric mill rhythms in intact crabs. Comp Biochem Physiol [A] 46:767-783.

Robertson RM, Laverack MS (1979) Oesophageal sensors and their modulatory influence on oesophageal peristalsis in the lobster, Homarus gammarus. Proc R Soc Lond B Biol Sci 206:235-263.

Rosen SC, Miller MW, Evans CG, Cropper EC, Kupfermann I (2000) Diverse synaptic connections between peptidergic radula mechanoafferent neurons and neurons in the feeding system of Aplysia. J Neurophysiol 83:1605-1620.

Selverston AI, Moulins M, editors (1987) The crustacean stomatogastric system: a model for the study of central nervous systems. Berlin: Springer.

Sigvardt KA, Mulloney B (1982) Sensory alteration of motor patterns in the stomatogastric nervous system of the spiny lobster Panulirus interruptus. J Exp Biol 97:137-152.

Soffe SR (1997) The pattern of sensory discharge can determine the motor response in young Xenopus tadpoles. J Comp Physiol [A] 180:711-715.

Weimann JM, Meyrand P, Marder E (1991) Neurons that form multiple pattern generators: identification and multiple activity patterns of gastric/ pyloric neurons in the crab stomatogastric system. J Neurophysiol 65:111-122.

Weiss KR, Shapiro E, Kupfermann I (1986a) Modulatory synaptic actions of an identified histaminergic neuron on the metacerebral cell of Aplysia. J Neurosci 6:2393-2402.

Weiss KR, Chiel HJ, Kupfermann I (1986b) Sensory function and gating of histaminergic neuron C2 in Aplysia. J Neurosci 6:2416-2426.

Wood DE, Manor Y, Nadim F, Nusbaum MP (2004) Inter-circuit control via rhythmic regulation of projection neuron activity. J Neurosci 24:7455-7463. 